\title{
URGENCY OF VIOLENCE SCREENING IN PREGNANT WOMEN: A SCOPING REVIEW
}

\author{
Eviana Maya Saputri, Mufdlilah
}

Universitas ‘Aisyiyah Yogyakarta

\begin{abstract}
Background: Partner violence during pregnancy might contribute to the clinical conditions of pregnant women. Early assessment and supportive response are required to improve clinical diagnosis and subsequent care. This scoping review aimed to identify the partner violence screening practices of community-based health care providers in pregnant women.

Subjects and Method: A scoping review method was conducted in eight stages including (1) Identification of study problems; (2) Determining priority problem and study question; (3) Determining framework; (4) Literature searching; (5) Article selection; (6) Critical appraisal; (7) Data extraction; and (8) Mapping. The search included PubMed, Science Direct, EBSCO, Wiley Online Library, and ProQuest databases. The inclusion criteria were English-language and fulltext articles published between 2010 and 2020. A total of 580 articles were obtained by the searched database. After the review process, eight articles were eligible for this review. The critical appraisal for searched articles were measured by Mix Methods Appraisal Tools (MMAT). The data were reported by the PRISMA flow chart.

Results: Two articles from developing countries (Zimbabwe and Kenya) and six articles from developed countries (Australia, Norway, Italy, and Sweden) met the inclusion criteria with a mixed-method, qualitative, and quantitative (cross-sectional) studies. The existing studies revealed that violence screening in pregnant women was effective to increase awareness of violence by their partners. Screening practice had an empowering effect on women to disclose the violence experienced. Barriers to the health care providers performing partner violence screening included: lack of knowledge, experience and training, confidence in undertaking the screening, taboo cultural practices, and absence of domestic violence screening policies.

Conclusion: Partner violence screening practice should be strongly considered at antenatal care visits. Further insights of community-based health care providers are required to perform effective screening.
\end{abstract}

Keywords: partner violence screening, pregnant women, health care providers

Correspondence:

Eviana Maya Saputri. Universitas 'Aisyiyah Yogyakarta. Jl. Siliwangi No. 63, Nogotirto, Gamping, Sleman, Yogyakarta, 55292. Email: evianamaya34@gmail.com. Mobile: +6281367470323.

The $7^{\text {th }}$ International Conference on Public Health

Solo, Indonesia, November 18-19, $2020 \mid 241$ https://doi.org/10.26911/the7thicph.03.61 